\title{
Comparative Study on the Macroscopic and Microscopic Properties of UHPC Mixed with Limestone Powder and Slag Powder
}

\author{
Menghui Yang $\mathbb{D}^{1},{ }^{1}$ Zhen He, ${ }^{2}$ Xia Chen, ${ }^{1}$ Mingxia $\mathrm{Li}^{1}{ }^{1}$ and Ziling Peng ${ }^{1}$ \\ ${ }^{1}$ Changjiang River Scientific Research Institute, Wuhan City, Hubei Province 430010, China \\ ${ }^{2}$ School of Water Resources and Hydropower Engineering, Wuhan University, Wuhan City, Hubei Province 430072, China \\ Correspondence should be addressed to Menghui Yang; yangmh@mail.crsri.cn
}

Received 22 January 2021; Revised 3 March 2021; Accepted 21 March 2021; Published 7 April 2021

Academic Editor: Bin Gong

Copyright ( 2021 Menghui Yang et al. This is an open access article distributed under the Creative Commons Attribution License, which permits unrestricted use, distribution, and reproduction in any medium, provided the original work is properly cited.

\begin{abstract}
This paper explores the development laws of the fluidity, compressive strength, and autogenous shrinkage of ultrahigh performance cement (UHPC) mixed with limestone powder (LP) and highly active ground slag powder (SP). A microscopic analysis was conducted on the hydration products and pore structures. Through quantitative research on the packing density and fractal dimension of particles in different systems, the relationship between particle characteristics and UHPC properties was established. As a result, the packing densities of the UHPC mixed solely with LP (binary system) and UHPC mixed with LP and silica fume (ternary system) are higher than those of UHPC mixed with the same amount of SP and the benchmark UHPC system; fractal dimension of particle size distribution is closely related to packing density. The LP-cement-silica fume ternary system was lowly hydrated, but it has a good grain composition and high density of slurry, which improved the compressive strength of UHPC. The compressive strength of UHPC mixed with 50\% LP witnessed a more obvious decline than that of the ternary system and the one with the same amount of SP. The reason lies in the decrease in slurry due to a lack of sufficient active constituents, and the hydration products were far from enough to fill the pores in the system. LP can also inhibit autogenous shrinkage to the greatest degree for the LP-mixed binary system performed best in such inhibition.
\end{abstract}

\section{Introduction}

Research on ultrahigh performance concrete (UHPC) and its application is one of the key directions of current cementbased material development. Mixed with fine short steel fiber and boasting a good particle size distribution, UHPC has a water-binder ratio below 0.25 and a $28 \mathrm{~d}$ compressive strength and tensile strength of at least $150 \mathrm{MPa}(100 \mathrm{MPa}$ in Chinese standard [1]) and $5 \mathrm{MPa}$. UHPC is such a highly stable material $[2,3]$ that it has been widely applied in long-span and ultra-long-span structures as well as buildings in severe environments.

UHPC has an extremely low water-binder ratio. The hydrations of cement and silica fume (SF) are only $30 \%-40 \%$ and about $30 \%$, respectively $[4,5]$. A large amount of unhydrated cement and SF particles only serves as a framework that fills the system, which constitutes a great waste of resources. Mean- while, there may be hidden danger in the volume stability of concrete owing to the great hydration heat and high heat release rate [6]. How to maximize the performance of its constituents has become an urgent problem to be solved. Therefore, less active and low-cost mineral admixture can be used to substitute a certain amount of cement. Limestone powder (LP) is a kind of fine powder with particle size less than $0.16 \mathrm{~mm}$ obtained through mechanically processing limestone. It is a rather affordable and accessible inactive mineral admixture that can be used to effectively reduce the $\mathrm{CO}_{2}$ emission during cement production [7]. Due to the adverse effect brought by the low activity of LP on the compressive strength in the later stage, the usual content of LP in concrete does not exceed 25\% [8-10]. Nevertheless, research showed that in UHPC mixed with cement and SF as well as that with an LP addition of over $50 \%$, the compressive strength can still be on the increase [11-22]. Zheng [23] found that in UHPC with a low water-binder ratio, packing 
density and pore size influence the mechanical properties and stability of hardened slurry by a degree higher than that of hydration of cementing material. Therefore, it is of vital importance to quantitatively clarify how LP amount and filling effect influence the properties of UHPC so as to provide guidance on the effective use of UHPC.

To explore how the filling effects of different LP amounts influence the macroscopic and microscopic properties of UHPC, in this paper, we adopted the compressible packing model (CPM) and fractal theory to calculate the packing densities of the binary system (LP or slag powder (SP) with cement) and ternary system (LP or SP with cement and $\mathrm{SF}$ ), as well as the fractal dimension of particle size distribution. Comparative studies were conducted to discover the development laws of the working performance, compressive strength, and autogenous shrinkage of UHPC mixed with LP and that with highly active fine SP. In the meantime, micromeasurement techniques such as scanning electron microscopy (SEM) and mercury intrusion porosimetry (MIP) were used to reveal the effect of LP on UHPC in microscopic aspects, including hydration product forms and pore structure parameters.

\section{Materials and Methods}

2.1. Materials. P.II52.5 ordinary Portland cement (OPC), SF, LP, and S105 SP were adopted. Their particle size distributions are shown in Figure 1 and their chemical composition and physical properties in Table 1 . Natural quartz sand was used as the aggregate, with a maximum particle size of $5 \mathrm{~mm}$, fineness modulus of 2.4, and apparent density of $2,650 \mathrm{~kg} / \mathrm{m}^{3}$. A polycarboxylate superplasticizer was adopted, whose properties satisfied the requirements in Concrete Admixtures (GB 8076-2008).

2.2. Mix Proportion. Nine groups of mix proportions were designed. LP and SP were mixed with cement and cement$\mathrm{SF}$, respectively, with a water-binder ratio of 0.18 , a bindersand ratio of $1: 1$, and polycarboxylate superplasticizers of $2.8 \%$. The mix proportions of UHPC are shown in Table 2.

\subsection{Methods}

2.3.1. Compressible Packing Model. The compressible packing model (CPM) was used to calculate the solid particle packing densities of all the constituents. Following a dozen years of experimental research, De Larrard, a French scientist in concrete materials, finally devised CPM [24]. Based on the linear packing model and solid suspension model, CPM overcomes the limitation of models devised by Toufar and Dewar, respectively, both of which considered only a single pattern. CPM, instead, takes into account the influence of particle size distribution and different packing patterns on packing density, contributing to accurate estimation of the packing density of the system with more than one solid particle mixed. So far, it has become the most applicable particle packing model in concrete research with extensive use $[25,26]$.

In $\mathrm{CPM}$, virtual packing density refers to the maximum packing density of a system mixed with more than one solid particle of constant shapes; residual packing density denotes

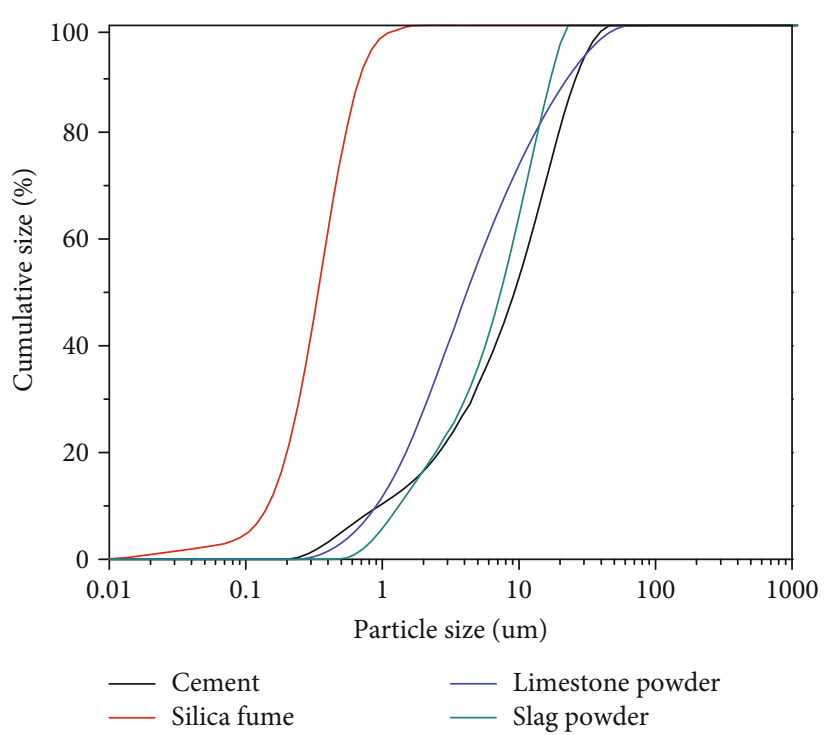

Figure 1: Particle size distributions of OPC, SF, LP, and SP.

the maximum packing density of a material mixed with particles of the same size in multielement solid particles per unit volume. The compaction index reflects the packing degrees dominated by particles of different sizes, which are the eigenvalues of different packing patterns of multiple constituents. In a binary system, solid particles are packed in two patterns (Figure 2): (a) relaxation effect and (b) wall attachment effect. The former shows that small particles prevent large ones from reaching the closest packing when the system is dominated by large particles; the latter shows that the closest packing is thwarted by the predominant small particles attached around the surface of large ones.

If the particle size $i$ is the closest, the virtual packing density and actual packing density $\left(\alpha_{t}\right)$ can be calculated by equations (1) and (6), respectively.

$$
r_{i}=\frac{\beta_{i}}{\left\{1-\sum_{j=1}^{i-1}\left[1-\beta_{i}+b_{i j} \beta_{i}\left((1-1) / \beta_{i}\right)\right] y_{j}-\sum_{j=i+1}^{n}\left(\left(1-a_{i j} \beta_{i}\right) / \beta_{j}\right) y_{j}\right\}},
$$

$$
\begin{gathered}
r=\min \left(r_{i}\right) 1 \leq i \leq n, \\
a_{i j}=\sqrt{1-\left(\frac{d_{j}}{d_{i}}\right)^{1.02}}(j=i+1, \cdots, n), \\
b_{i j}=1-\left(\frac{1-d_{i}}{d_{j}}\right)^{1.50}(j=1, \cdots, i-1), \\
K=\sum_{i=1}^{n} K_{i}=\sum_{i=1}^{n} \frac{y_{i} / \beta_{i}}{\left(1 / \alpha_{t}\right)-\left(1 / r_{i}\right)}, \\
\alpha_{t}=\frac{\rho_{p}}{\rho_{a}} .
\end{gathered}
$$

In the equations, $r_{i}$ is the virtual packing density, $\beta_{i}$ is the residual packing density, $y_{i}$ is the volume traction of particles 
TABLE 1: Chemical composition and physical properties of OPC, SF, LP, and SP.

\begin{tabular}{|c|c|c|c|c|c|c|c|c|c|c|}
\hline \multirow[t]{2}{*}{ Material } & \multirow[t]{2}{*}{$\mathrm{SiO}_{2}$} & \multirow[t]{2}{*}{$\mathrm{Al}_{2} \mathrm{O}_{3}$} & \multirow[t]{2}{*}{$\mathrm{Fe}_{2} \mathrm{O}_{3}$} & \multirow[t]{2}{*}{$\mathrm{Cao}$} & \multirow[t]{2}{*}{$\mathrm{MgO}$} & \multirow[t]{2}{*}{$\mathrm{SO}_{3}$} & \multirow[t]{2}{*}{ Specific area $\left(\mathrm{m}^{2} / \mathrm{kg}\right)$} & \multirow[t]{2}{*}{ Density $\left(\mathrm{kg} / \mathrm{m}^{3}\right)$} & \multicolumn{2}{|c|}{$\begin{array}{c}\text { Activity } \\
\text { index (\%) }\end{array}$} \\
\hline & & & & & & & & & $7 \mathrm{~d}$ & $28 \mathrm{~d}$ \\
\hline OPC & 18.2 & 3.7 & 3.3 & 66.1 & 2.4 & 4.5 & 371 & 3,090 & - & - \\
\hline SF & 95.5 & - & - & 1.0 & 0.7 & - & 18,100 & 2,320 & 98 & 108 \\
\hline LP & 1.6 & 0.2 & 0.2 & 54.2 & 5.0 & 0.2 & 648 & 2,680 & - & 64 \\
\hline SP & 29.2 & 12.7 & 1.0 & 44.4 & 8.3 & 2.1 & 520 & 3,050 & 97 & 108 \\
\hline
\end{tabular}

TABLE 2: Test results for packing density, fluidity, and compressive strength.

\begin{tabular}{|c|c|c|c|c|c|c|c|c|c|}
\hline \multirow[t]{2}{*}{ No. } & \multirow[t]{2}{*}{ Water-binder ratio } & \multirow[t]{2}{*}{ OPC (\%) } & \multirow[t]{2}{*}{ SF $(\%)$} & \multirow[t]{2}{*}{ LP (\%) } & \multirow[t]{2}{*}{ SP (\%) } & \multirow[t]{2}{*}{ Fluidity (mm) } & \multicolumn{2}{|c|}{$\begin{array}{l}\text { Compressive } \\
\text { strength } \\
(\mathrm{MPa})\end{array}$} & \multirow[t]{2}{*}{ Packing density } \\
\hline & & & & & & & $7 \mathrm{~d}$ & $28 \mathrm{~d}$ & \\
\hline $\mathrm{cl}$ & 0.18 & 100 & - & - & - & 375 & 87.1 & 108.1 & 0.672 \\
\hline $\mathrm{cs} 11$ & 0.18 & 70 & 10 & 20 & - & 431 & 89.6 & 114.0 & 0.705 \\
\hline $\mathrm{cs} 12$ & 0.18 & 60 & 10 & 30 & - & 407 & 92.3 & 114.7 & 0.709 \\
\hline $\mathrm{csl} 3$ & 0.18 & 50 & 10 & 40 & - & 390 & 94.6 & 115.9 & 0.717 \\
\hline $\mathrm{cl} 4$ & 0.18 & 50 & - & 50 & - & 385 & 78.9 & 91.8 & 0.704 \\
\hline $\operatorname{css} 1$ & 0.18 & 70 & 10 & - & 20 & 425 & 93.0 & 121.7 & 0.683 \\
\hline $\operatorname{css} 2$ & 0.18 & 60 & 10 & - & 30 & 400 & 94.2 & 123.3 & 0.687 \\
\hline $\operatorname{css} 3$ & 0.18 & 50 & 10 & - & 40 & 381 & 96.4 & 126.8 & 0.688 \\
\hline cs 4 & 0.18 & 50 & - & - & 50 & 369 & 91.4 & 119.0 & 0.668 \\
\hline
\end{tabular}

of different sizes, $a_{i j}$ and $b_{i j}$ are the relaxation effect factor and watch attachment effect factor, $\alpha_{t}$ is the packing density of the particles, $\rho_{a}$ is the actual density of material, $\rho_{p}$ is the absolute packing density, and $K$ is the compaction index.

2.3.2. Fractal Dimension of Particle Size Distribution. Fractal dimension of particle size distribution was used to characterize the surface roughness of solid particles of all the constituents. The results indicated [27] that self-similarity (fractal structure) was shown in the particle size distribution. The fractal dimension is the quantitative parameter used to describe fractal characteristics because it is related to the property parameters of materials [28]. A higher fractal dimension makes it easier for powder particles to aggregate with higher fluidity. The fractal characteristics, if any, meet [29]

$$
S(x)=k^{*}\left(\frac{x}{X}\right)^{3-D}
$$

where $S(x)$ is the cumulative distribution curve, $D$ is the particle size distribution, $k$ is a constant, $x$ is the particle size, and $X$ is the maximum particle size.

Taking the logarithms of both sides of equation (7), we obtain

$$
\lg S(x)=\lg k+(3-D) * \lg (X-x)
$$

which is a linear regression equation. Let the slope $(3-D)$ $=k$ (a constant), and then, the fractal dimension is

$$
D=3-k
$$

2.3.3. Experimental Methods. Standard curving was adopted, with the temperature being $20^{\circ} \mathrm{C} \pm 5^{\circ} \mathrm{C}$ and the relative humidity being over $95 \%$. The fluidity test was conducted in accordance with Test Method for Fluidity of Cement Mortar (GB/T 2419-2005). Compressive strength was measured based on Method of Testing Cements-Determination of Strength (GB/T 17671-1999), and the compressive strength of a $40 \mathrm{~mm} \times 40 \mathrm{~mm} \times 160 \mathrm{~mm}$ specimen was measured after standard curing for $7 \mathrm{~d}$ and $28 \mathrm{~d}$. Autogenous shrinkage was tested according to Standard for Test Methods of Long-term Performance and Durability of Ordinary Concrete (GB/T 50082-2009). The autogenous shrinkage of a $100 \mathrm{~mm} \times 100$ $\mathrm{mm} \times 515 \mathrm{~mm}$ specimen was measured via a noncontact concrete shrinkage deformer.

A $20 \mathrm{~mm} \times 20 \mathrm{~mm} \times 20 \mathrm{~mm}$ net paste cubic specimen was prepared based on the mix proportion in the macroscopic property test of UHPC. The prepared specimen was placed in the standard curing chamber for $1 \mathrm{~d}$, demolded, soaked in water $\left(20^{\circ} \mathrm{C} \pm 1^{\circ} \mathrm{C}\right)$ for the set curing ages $(7 \mathrm{~d}$ and $28 \mathrm{~d}$ ), and then taken out to be broken into small pieces, from the center of which samples were taken. After the hydration was terminated through absolute ethyl alcohol, 


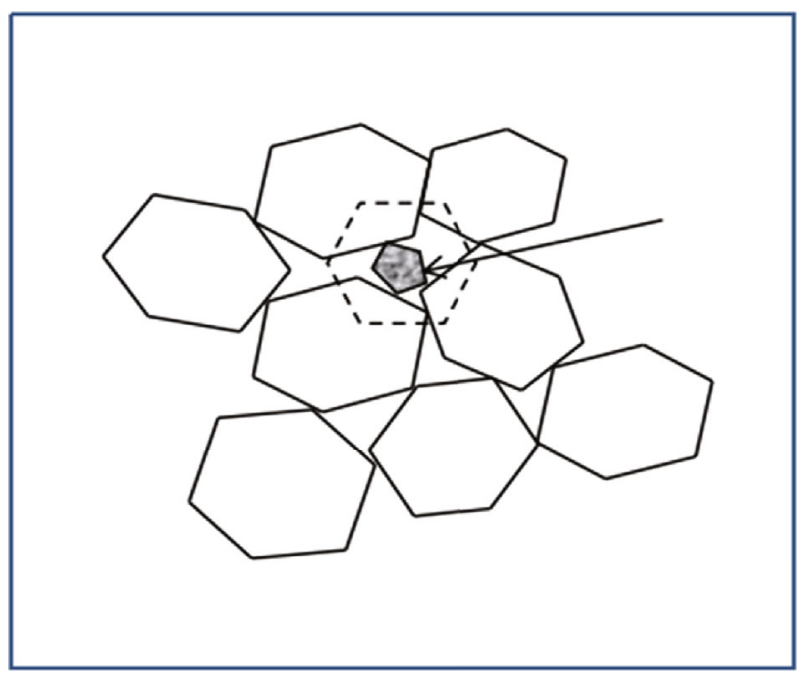

(a) Relaxation effect

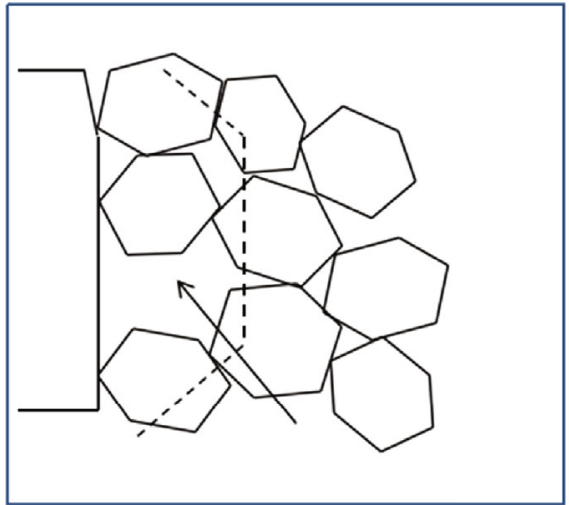

(b) Wall attachment effect

Figure 2: Packing patterns.

TABLE 3: Fractal dimensions of particle size distributions and corresponding regression equations.

\begin{tabular}{lccc}
\hline No. & Regression equation & $\begin{array}{c}\text { Correlation } \\
\text { coefficient } r\end{array}$ & $\begin{array}{c}\text { Fractal } \\
\text { dimension } D\end{array}$ \\
\hline c1 & $y=0.9541 x+0.7398$ & 0.87 & 2.0459 \\
cs11 $y=0.7183 x+0.6719$ & 0.90 & 2.2817 \\
cs12 $y=0.7178 x+0.6688$ & 0.90 & 2.2822 \\
cs13 $y=0.7172 x+0.6656$ & 0.90 & 2.2828 \\
c14 $y=0.9272 x+0.7583$ & 0.89 & 2.0728 \\
css1 $y=0.7204 x+0.6529$ & 0.91 & 2.2796 \\
css2 $y=0.7193 x+0.6545$ & 0.91 & 2.2807 \\
css3 $y=0.7182 x+0.6656$ & 0.91 & 2.2818 \\
cs4 $y=1.0833 x+0.6123$ & 0.90 & 1.9167 \\
\hline
\end{tabular}

the sample was reserved in a vacuum drying oven and then analyzed by SEM and MIP.

\section{Results and Discussion}

3.1. Results. Test results of fluidity, compressive strength, and packing density calculated through CPM are shown in Table 2, and the fractal dimension of particle size distribution and the regression equation are given in Table 3. Group c refers to the system mixed solely with cement; groups csl and css denote the ternary systems in which LP (csl) and SP (css) are, respectively, mixed with cement and SF; and groups $\mathrm{cl}$ and cs refer to the binary systems in which LP (cl) and SP (cs) are mixed with cement, respectively.

3.2. Packing Density. Seen from the test results of packing density in Table 2 and Figure 3, with the same amount, the packing densities of both binary and ternary systems of LP mixed with cement or cement-SF were higher than those of SP. The packing densities of ternary systems were both higher than those of corresponding binary systems as well as the benchmark system. As for the reason, LP particles selected in this research were finer than cement and SP particles and these tiny particles filled the pores in cement to improve the packing density. On the other hand, after being mixed with cement-SF, the ternary systems of LP and SP had more evident difference in particle sizes than their corresponding binary systems. It had a wider particle size distribution and better grain composition. Therefore, the packing density of the ternary system was higher than that of the binary system.

3.3. Fractal Dimension of Particle Size Distribution. According to the calculation results of fractal dimensions (Table 2 and Figure 4), the correlation coefficients ranged from 0.87 to 0.91 , signaling good linear correlations. With the increase in LP and SP amount, the fractal dimensions of their corresponding binary and ternary systems witnessed slight rises. The fractal dimension of the LP ternary system was higher than that of the SP ternary system; the fractal dimensions of these two ternary systems were both higher than those of the binary and benchmark systems. This indicates that LP mixed in the ternary system had increased fine particles to bring about a more complex overall form and then higher fractal dimensions. The calculation results of all the fractal dimensions were well correlated with those of corresponding packing densities. On the whole, a higher fractal dimension resulted in a higher packing density.

3.4. Fluidity. The test results of fluidity (Table 2 and Figure 5) showed that certain amounts of LP or SP in the ternary systems both enhanced the fluidity of the concrete, but the fluidity dropped gradually after the amounts of LP or SP reached certain levels. Some water in concrete 


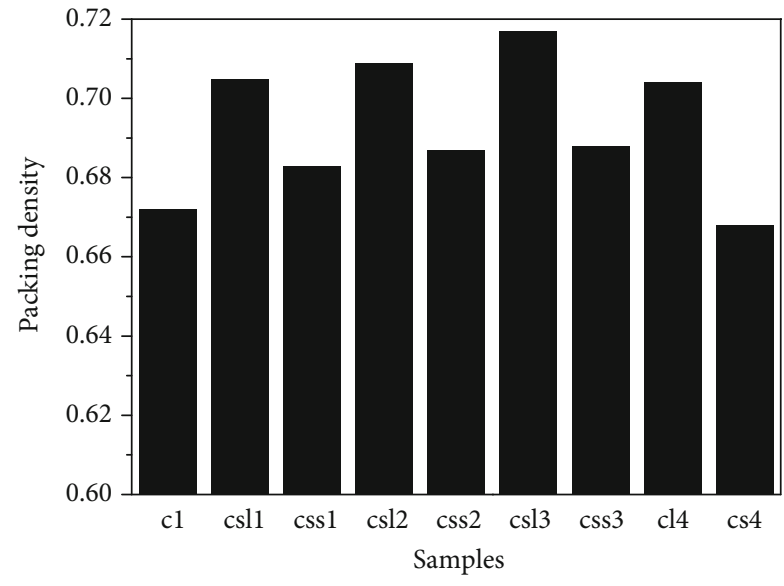

FIgURE 3: Comparison of particle size distributions.

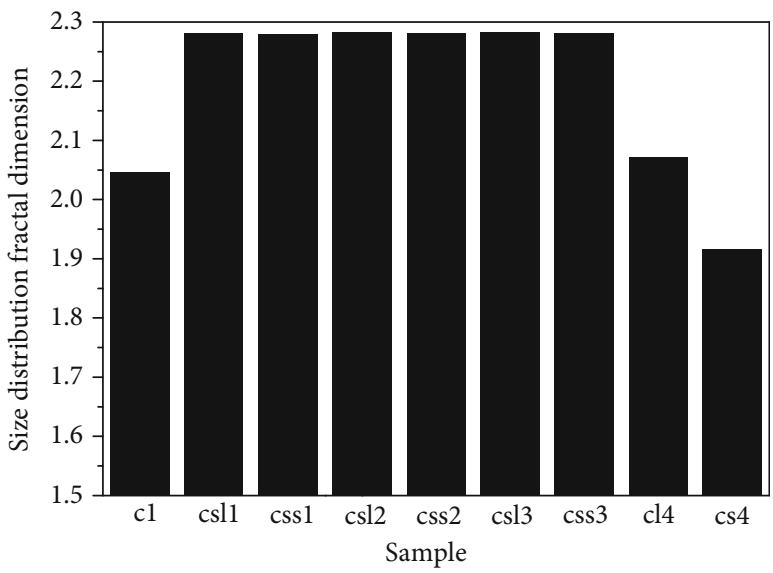

FIgURE 4: Comparison of fractal dimensions of particle size distributions.

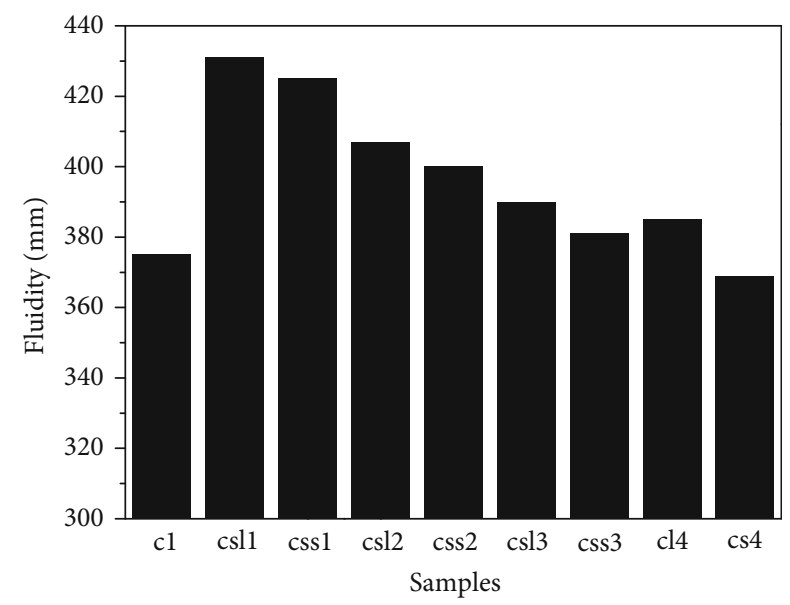

FIGURE 5: Comparison of fluidities.

mix was used to fill the pores in grain skeleton, and the rest was used to realize the workability. Since the water amount remained unchanged, LP or SP in the ternary system elevated the packing densities and reduced the water

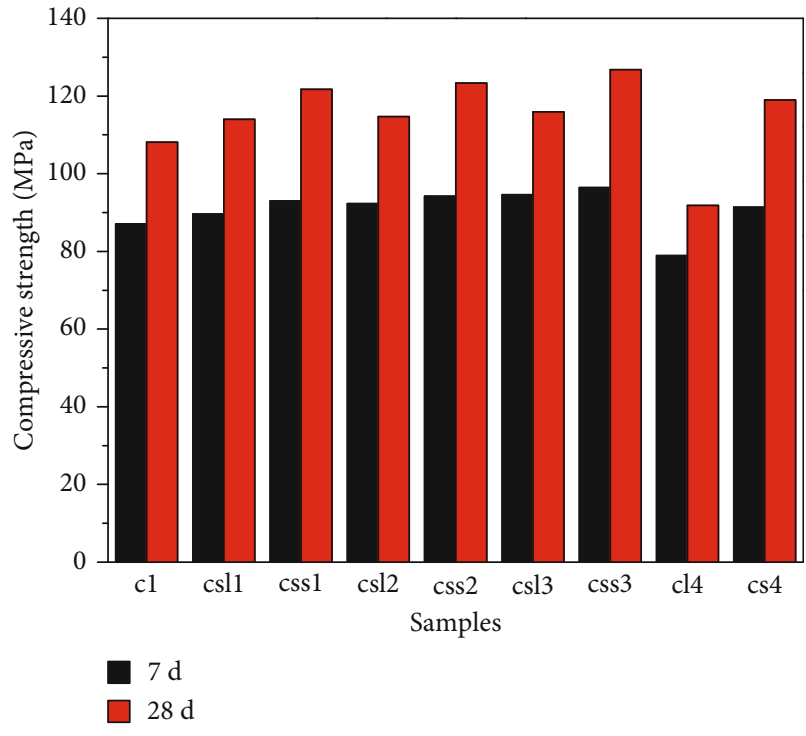

FIgURE 6: Comparison of compressive strength.

needed to fill the pores. Hence, more free water was flowing outside the pores, resulting in a higher fluidity. Moreover, a higher fractal dimension made it easier for powder particles to aggregate and hence resulted in a higher packing density and better fluidity of the aggregate. The fractal dimension and packing density of the LP ternary system were both higher than those of the SP ternary system (LP = SP in amount). As a consequence, the fluidity of the LP ternary system was higher than that of the SP ternary system. With more LP or SP added, the specific area grew and more water was absorbed by the surface layer of particles so that some free water released by the filling was counteracted. Therefore, when LP or SP being added exceeded a certain amount, fluidity fell as LP or SP increased. However, the fluidity of the system mixed solely with 50\% LP was still higher than that of the benchmark system.

3.5. Compressive Strength. It can be seen from the test results (Table 2 and Figure 6) that the $7 \mathrm{~d}$ and $28 \mathrm{~d}$ compressive strength of the LP and SP ternary system went up with more LP or SP added and was constantly higher than that of the benchmark system.

The compressive strengths of the SP binary and ternary systems were higher than those of the LP binary and ternary systems on $7 \mathrm{~d}$ and $28 \mathrm{~d}$. The compressive strength of the SP ternary system witnessed a slighter increase compared to that of the LP ternary system. The drop in 50\% LP binary system was more obvious than that in $50 \%$ SP binary system. Specifically, the $7 \mathrm{~d}$ and $28 \mathrm{~d}$ compressive strengths fell by $13.7 \%$ and $24.6 \%$, respectively, but still stood at $90.6 \%$ and $85 \%$ of those of the benchmark system, which was radically different to the decline seen in compressive strength (especially in the later stage) of OPC mixed with a high amount of LP [30]. Compared with Figure 2, the packing densities of all the 

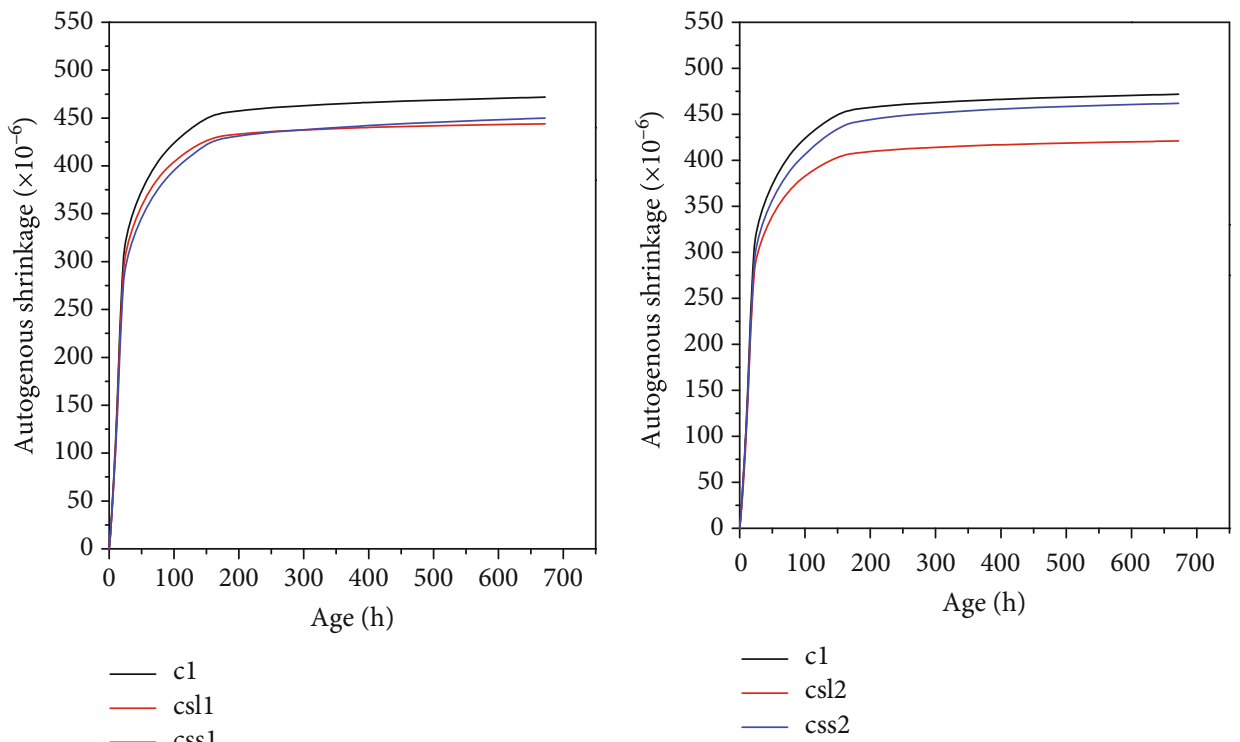

(a) csl1-css 1
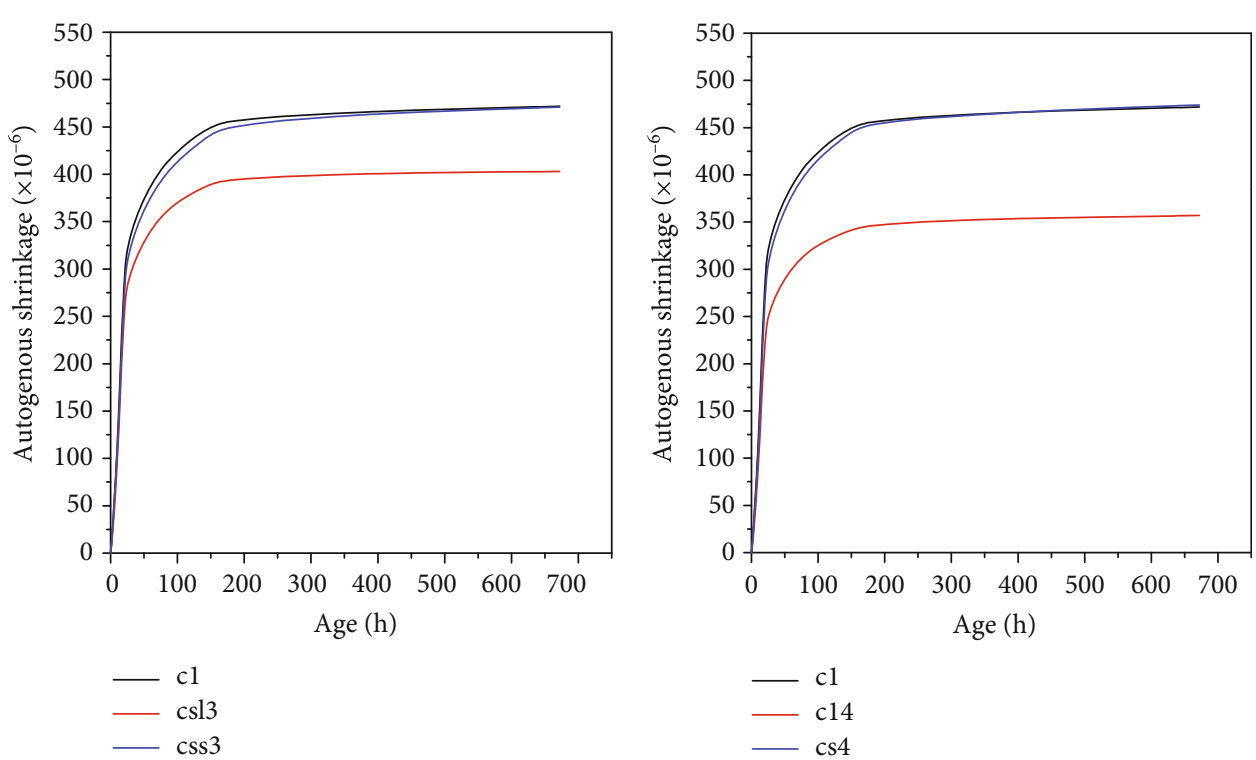

(c) $\operatorname{csl} 3-\operatorname{css} 3$

(d) cl4-cs4

FIGURE 7: Comparison of autogenous shrinkage. 


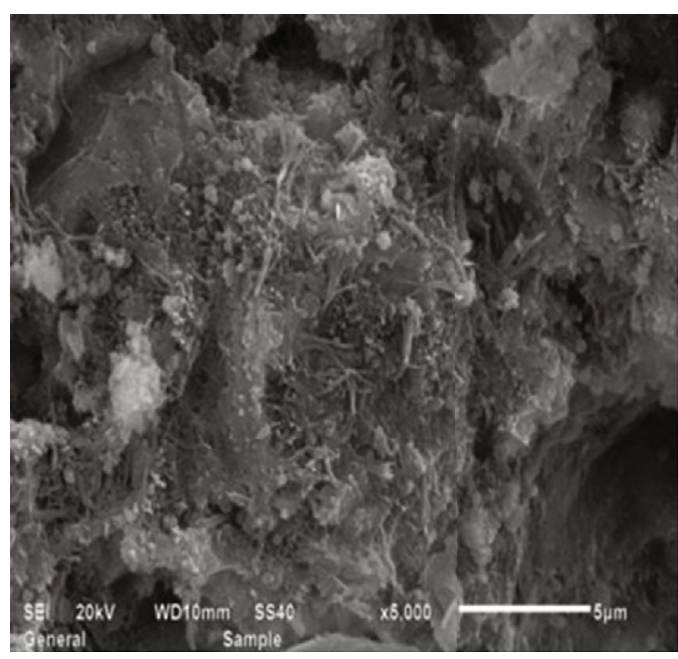

(a) $\mathrm{cl}, 28 \mathrm{~d}(\times 5,000)$

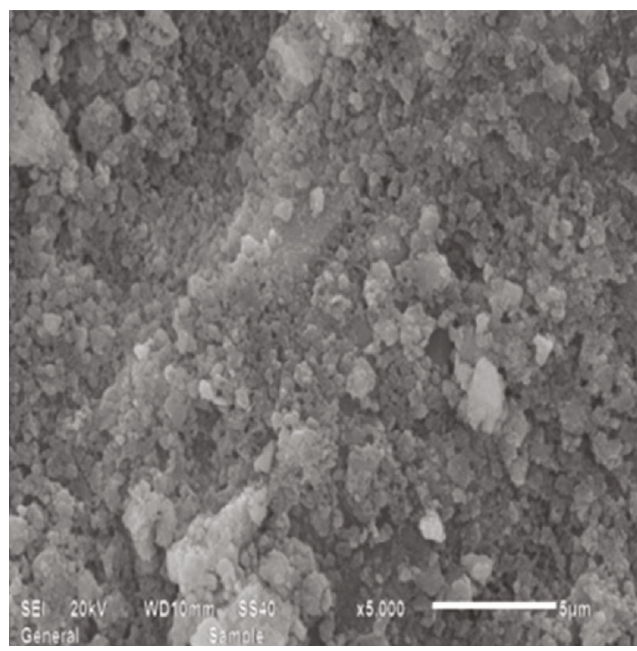

(c) $\mathrm{cl} 4,28 \mathrm{~d}(\times 5,000)$

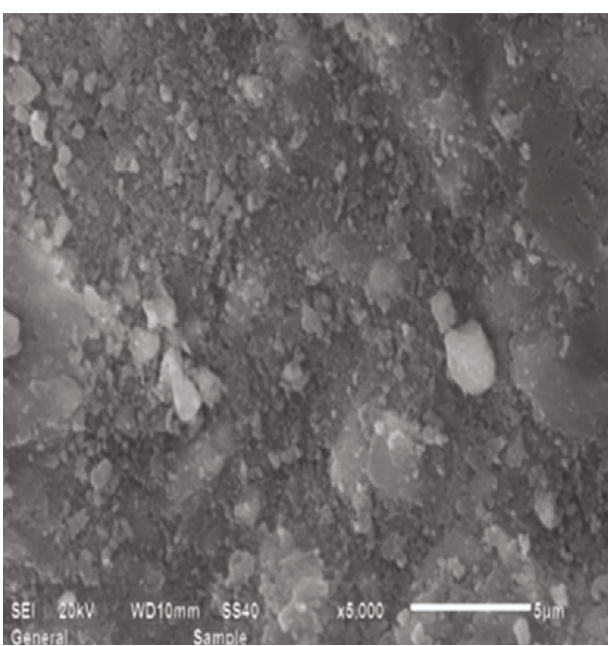

(b) csl1, $28 \mathrm{~d}(\times 5,000)$

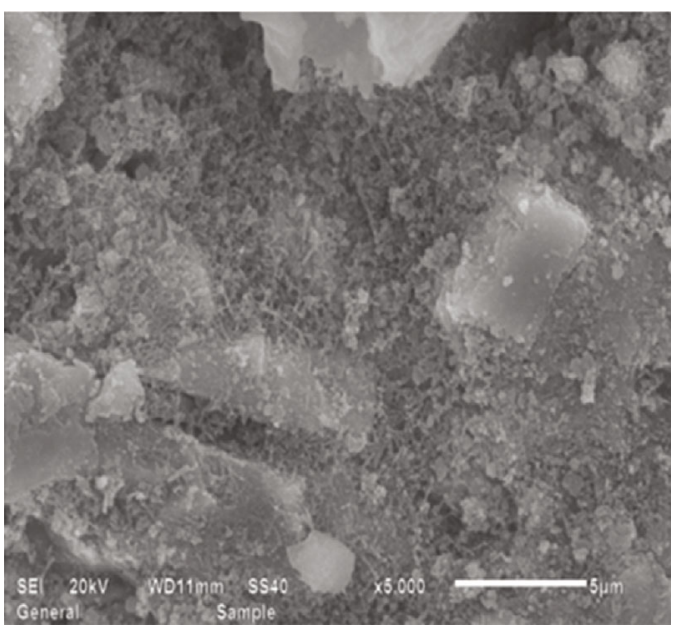

(d) $\operatorname{css} 1,28 \mathrm{~d}(\times 5,000)$

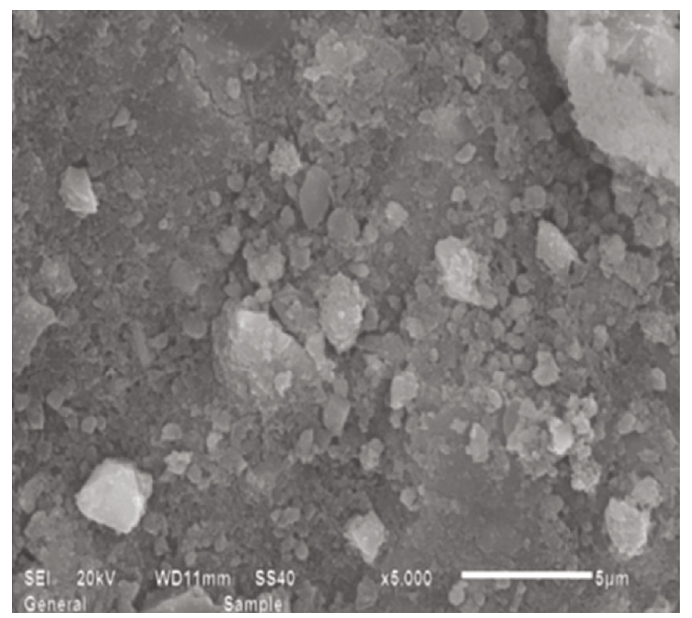

(e) $\operatorname{cs} 4,28 \mathrm{~d}(\times 5,000)$

Figure 8: The $28 \mathrm{~d}$ SEM images. 
systems mixed with LP were higher than those mixed with SP. Thus, with a large amount of cement particles unhydrated in a low water-binder ratio, the added LP increased the packing density and was partially made up for the negative influence of LP inertia on the later compressive strength. A higher fractal dimension led to a higher surface energy, stronger absorption, and higher compressive strength.

3.6. Autogenous Shrinkage. With water-binder ratio decreasing, autogenous shrinkage caused by chemical (spontaneous) shrinkage and self-desiccation accounts for a higher proportion of the total. Burrows [31] demonstrated that the autogenous shrinkages occupy 36\%, 50\%, 63\%, and $80 \%$ at water-binder ratios of $0.38,0.31,0.27$, and 0.22 , for which autogenous shrinkage cannot be ignored in UHPC studies.

The results of the autogenous shrinkage test on the LP and SP mixed UHPC are shown in Figure 7. Research results showed that LP inhibited autogenous shrinkage obviously and more LP led to less shrinkage. The inhibition in the LP binary system was more apparent than that in the LP ternary system. On the one hand, more LP resulted in more unhydrated particles, in this way suppressing the autogenous shrinkage of the concrete. On the other hand, the increase in packing density reduced the water for filling, releasing more free water and slowing down the decline rates of internal relative humidity of the concrete. In addition, the expansibility of $\mathrm{C}_{3} \mathrm{~A} \cdot \mathrm{Ca}-$ $\mathrm{CO}_{3} \cdot 11 \mathrm{H}_{2} \mathrm{O}$ generated from the reaction between $\mathrm{CaCO}_{3}$ in $\mathrm{LP}$ and $\mathrm{C}_{3} \mathrm{~A}$ in cement particles compensated for the shrinkage of the concrete [32].

SP exerted a more complicated influence on autogenous shrinkage characterized by inhibition within a certain amount of addition and promotion with too much SP added. Autogenous shrinkage witnessed even more remarkable surge in the later stage and the later autogenous shrinkage rates of css 3 and cs 4 were converging to that of the benchmark system. Research showed [33] that the influence of SP on the autogenous shrinkage of the concrete is associated with fineness. LP with fineness close to that of cement particles brought about a slight reduction in autogenous shrinkage of the concrete with more SP added. The high fineness and highly active SP in this experiment exerted just a bit suppression on autogenous shrinkage.

\subsection{Hydration Behavior and Microstructure}

3.7.1. Forms of Hydration Products. The $28 \mathrm{~d}$ SEM images of LP or SP binary and ternary systems are shown in Figure 8. According to Figure 8(a), hydration products such as $\mathrm{C}-\mathrm{S}-\mathrm{H}$ fiber-like gel, needle-like ettringite, and flaky $\mathrm{Ca}(\mathrm{OH})_{2}$ were generated in the benchmark system on $28 \mathrm{~d}$, but they were so incompletely hydrated that they contain many pores. Through the comparison of the SEM images of LP binary and ternary systems (Figures 8 (b) and 8(c)) and that of the benchmark system, we can find that the LP ternary system witnessed obviously less hydration, fewer hydration products (no fiber-like gel and flaky prod-
TABLE 4: Test results of pore structures of hardened slurry.

\begin{tabular}{lcccccccc}
\hline & \multirow{3}{*}{ No. } & $\begin{array}{c}\text { Age } \\
(\mathrm{d})\end{array}$ & $\begin{array}{c}\text { Porosity } \\
(\%)\end{array}$ & \multicolumn{6}{c}{ Pore size distribution $(\%) / \mathrm{nm}$} \\
& & & $5-$ & $20-$ & $50-$ & $100-$ & $>200$ \\
c1 & 7 & 14.3 & 17.6 & 50.1 & 25.4 & 4.3 & 1.4 & 1.2 \\
& 28 & 10.7 & 20.1 & 52.3 & 22.8 & 2.7 & 1.1 & 1.0 \\
& 7 & 13.6 & 17.1 & 50.9 & 25.1 & 4.8 & 1.0 & 1.1 \\
csl1 & 28 & 10.2 & 20.8 & 51.6 & 22.7 & 3.1 & 0.9 & 0.9 \\
& 7 & 13.2 & 18.0 & 51.2 & 26.2 & 3.2 & 0.8 & 0.9 \\
cs13 & 28 & 9.7 & 21.2 & 52.1 & 24.0 & 1.4 & 0.6 & 0.7 \\
& 7 & 16.1 & 15.5 & 46.7 & 27.1 & 6.4 & 2.4 & 1.9 \\
cl4 & 28 & 13.3 & 18.3 & 48.8 & 25.2 & 4.1 & 2.0 & 1.6 \\
& 7 & 12.2 & 18.7 & 53.9 & 23.2 & 2.4 & 1.1 & 0.7 \\
css1 & 28 & 10.0 & 20.6 & 54.4 & 21.5 & 2.0 & 0.9 & 0.6 \\
& 7 & 12.8 & 17.7 & 53.4 & 24.2 & 2.6 & 1.2 & 0.9 \\
css3 & 28 & 9.4 & 22.0 & 55.1 & 20.6 & 1.0 & 0.8 & 0.5 \\
& 7 & 13.4 & 17.4 & 53.1 & 24.8 & 2.2 & 1.4 & 1.1 \\
cs4 & 28 & 9.9 & 20.4 & 54.1 & 21.9 & 1.7 & 1.1 & 0.8 \\
\hline
\end{tabular}

uct), and more unhydrated particles exposed. On the contrary, less pores and more compact slurry were seen, which indicated that LP had led to better grain composition with cement and SF and thus a good filling effect. The LP binary system was poorly hydrated compared to the LP ternary system, so it was looser with more pores.

Compared with LP systems, the corresponding SP binary and ternary systems were better hydrated with more hydration products on $28 \mathrm{~d}$. The slurry was compact and replete with fiber-like C-S-H.

3.7.2. Pore Structure. Mercury intrusion porosimetry (MIP) was adopted to measure the pore structures of all the systems. The results are shown in Table 4 and Figure 9. Mehta and Monteiro [34] classified pores into four grades in terms of size, namely, $<4.5 \mathrm{~nm}, 4.5-50 \mathrm{~nm}, 50-100 \mathrm{~nm}$, and $>100 \mathrm{~nm}$. What is more, pores with sizes over $100 \mathrm{~nm}$ were considered harmful to the strength and permeability of the concrete while the rest was regarded less harmful or even unharmful. $\mathrm{Wu}$ and Lian [35] divided pores into these groups according to size-related harm: unharmful pore $(<20 \mathrm{~nm})$, slightly harmful pore $(100-200 \mathrm{~nm})$, harmful pore $(100-200 \mathrm{~nm})$, and seriously harmful pore $(>200 \mathrm{~nm})$. At the same time, they proposed that concrete properties could be enhanced by increase in pores less than $50 \mathrm{~nm}$ and decrease in pores more than $100 \mathrm{~nm}$. In this experiment, pores are classified into six groups: $<5 \mathrm{~nm}, 20-50 \mathrm{~nm}, 50-100 \mathrm{~nm}, 100-200 \mathrm{~nm}$, and $>200 \mathrm{~nm}$.

The results showed that the porosity of the SP ternary system was slightly lower than that of the LP ternary system (LP $=$ SP in amount). Compared with the 50\% LP-mixed binary system, the porosity of the binary system mixed solely with 50\% SP witnessed a sharp increase, along with more harmful pores and seriously harmful pores. Specifically, despite the higher packing density, the LP binary system failed to generate enough hydration products to fill the 


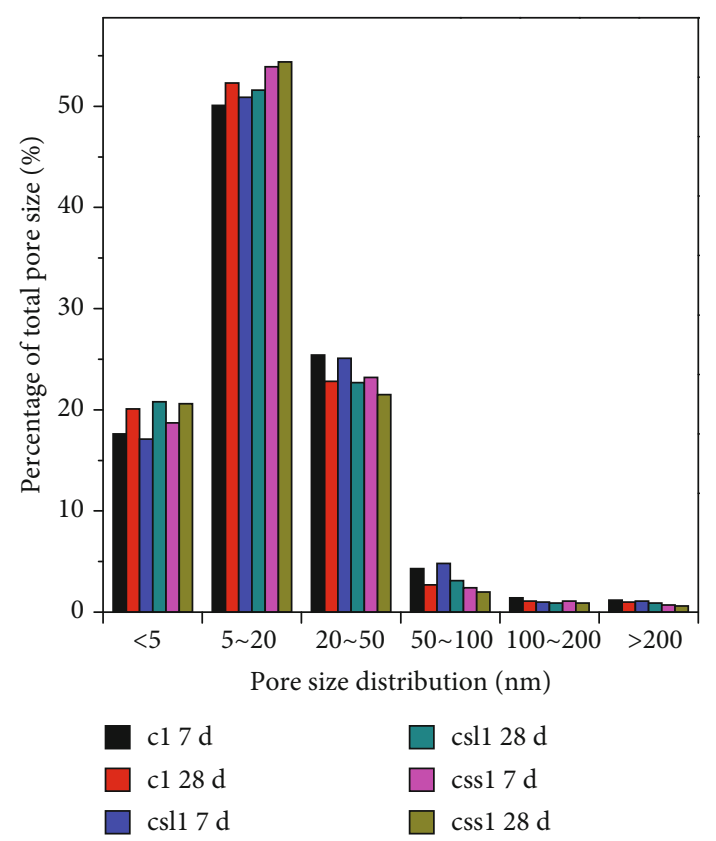

(a) $\operatorname{csl} 1-\operatorname{css} 1$

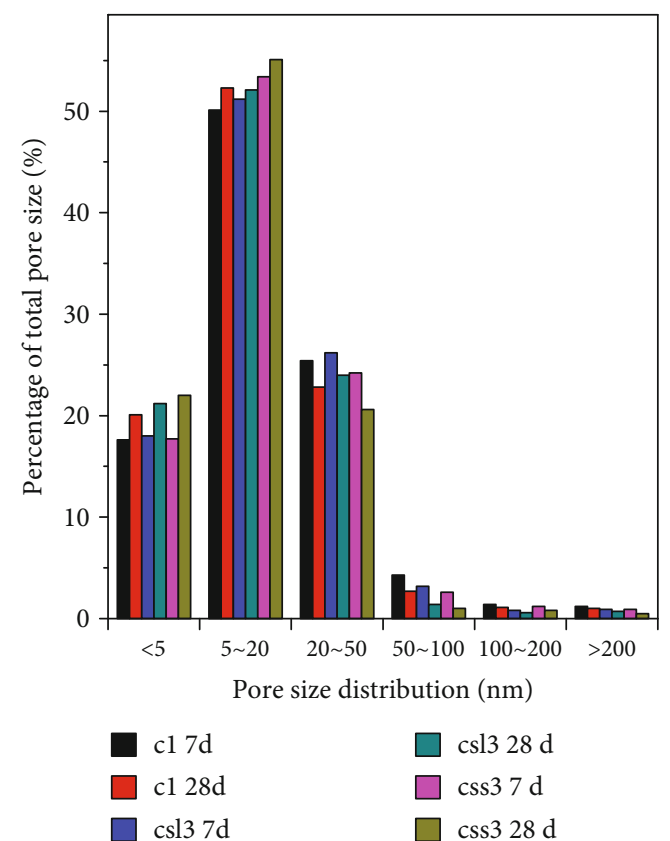

(b) $\operatorname{csl} 3-\operatorname{css} 3$

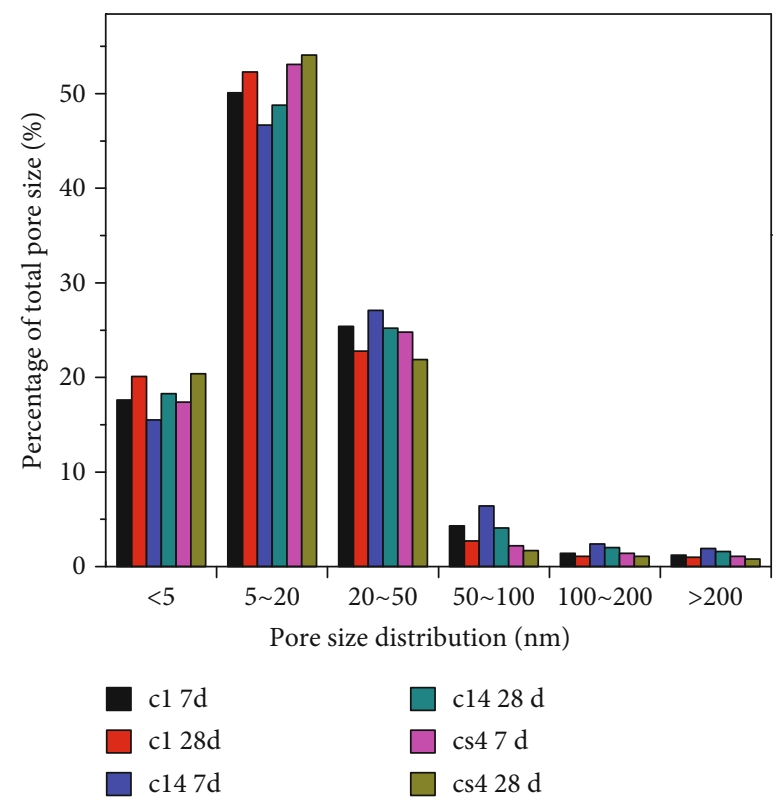

(c) $\mathrm{cl} 4-\mathrm{cs} 4$

FIgURE 9: Comparison of pore size distributions.

internal pores for a lack of active constituents, thus leading to greater porosity. The law of pore structure results basically agreed with that of compressive strength results.

\section{Conclusions}

(1) The packing density and fractal dimension of LP binary and ternary systems were higher than those of the SP binary and ternary system ( $L P=S P$ in amount) and the benchmark system, revealing why
UHPC with much LP added has excellent physiomechanical properties

(2) Within a certain amount, LP could improve the UHPC fluidity of the binary and ternary systems. The good grain composition of the LP ternary system resulted in a higher compressive strength of UHPC. Despite the large decline in the compressive strength of the LP binary system, the $7 \mathrm{~d}$ and $28 \mathrm{~d}$ compressive strengths still stood at $90.6 \%$ and $85 \%$ of those of the benchmark system. 
(3) LP greatly inhibited the autogenous shrinkage of UHPC. The autogenous shrinkage dropped with more LP added, and the inhibition of LP in binary systems was more obvious than that in ternary systems.

(4) From the test results of the hydrohydration product morphology and pore structure parameters, the hydration degrees of the LP-mixed binary and ternary systems were significantly lower than those of the SP-mixed systems and benchmark system. However, due to the excellent grain composition in the ternary system, the density of the gel system was higher than that of the baseline group, and there was no significant decrease compared with systems mixed with the same amount of SP. The binary system mixed with $50 \%$ LP could not generate enough hydration products to fill the pores in the system, resulting in an increased porosity and decreased slurry density.

\section{Data Availability}

Some or all data, models, or codes generated or used during the study are available from the corresponding author on request.

\section{Conflicts of Interest}

No conflict of interest exists in the submission of this manuscript.

\section{Acknowledgments}

We thank Yaqi Gong for the support and suggestions on this study. This work was supported by the Fundamental Research Funds for the Central Universities of Ministry of Education of China (CKSF2019183/CL, CKSF2019195/CL) and the National Natural Science Foundation of China (51779019).

\section{References}

[1] P. Y. Yan, M. Z. An, Q. Dou et al., Code for Reactive Powder Concrete, China Standards Press, Beijing, 2015.

[2] S. Aaleti, B. Petersen, and S. Sritharan, "Design guide for precast UHPC waffle deck panel system, including connections," Transportation, vol. 63, no. 6, pp. 128-132, 2014.

[3] E. Brühwiler and E. Denarié, "Rehabilitation and strengthening of concrete structures using ultra-high performance fibre reinforced concrete," Structural Engineering International, vol. 23, no. 4, pp. 450-457, 2018.

[4] A. Korpa, T. Kowald, and R. Trettin, "Phase development in normal and ultra high performance cementitious systems by quantitative X-ray analysis and thermoanalytical methods," Cement and Concrete Research, vol. 39, no. 2, pp. 450-457, 2009.

[5] K. Habel, M. Viviani, E. Denarié, and E. Brühwiler, “Development of the mechanical properties of an ultra-high performance fiber reinforced concrete (UHPFRC)," Cement and Concrete Research, vol. 36, no. 7, pp. 450-457, 2006.
[6] J. Z. Liu, W. Sun, C. W. Miao, and J. P. Liu, "Research on hydronation heat of low water-binder ratio slurry for ultrahigh performance concrete," Journal of Building Materials, vol. 13, no. 2, pp. 139-143, 2010.

[7] G. H. Rau, K. G. Knauss, W. H. Langer, and K. Caldeira, "Reducing energy-related $\mathrm{CO}_{2}$ emissions using accelerated weathering of limestone," Energy, vol. 32, no. 8, pp. 14711477, 2007.

[8] G. L. Leo and K. H. Albert, “Adding limestone fines as cementitious paste replacement to improve tensile strength, stiffness and durability of concrete," Cement and Concrete Composite, vol. 60, pp. 17-24, 2015.

[9] D. R. Fang, J. D. Yang, C. E. Du, S. L. Zhang, and JC 600-2002, Limestone Portland Cement, China Standards Press, Beijing, 2002.

[10] D. P. Bentz, A. Ardani, T. Barrett et al., "Multi-scale investigation of the performance of limestone in concrete," Construction and Building Materials, vol. 75, pp. 1-10, 2015.

[11] E. Denarié, Recommendations for the Tailoring of UHPFRC Recipes for Rehabilitation, Deliverable ARCHESD06, Lausanne, Switzerland, École Polytechnique Fédérale de Lausanne, 2009.

[12] W. Huang, H. Kazemi-Kamyab, W. Sun, and K. Scrivener, "Effect of cement substitution by limestone on the hydration and microstructural development of ultra-high performance concrete (UHPC)," Cement and Concrete Composites, vol. 77, pp. 450-457, 2017.

[13] G. Habert, E. Denarié, A. Šajna, and P. Rossi, "Lowering the global warming impact of bridge rehabilitations by using ultra high performance fibre reinforced concretes," Cement and Concrete Composites, vol. 38, no. 2, pp. 450-457, 2013.

[14] Y. G. Zhang, J. Qiu, Y. Zhang, and Y. Wei, “The adoption of ELM to the prediction of soil liquefaction based on CPT," Natural Hazards, 2021.

[15] Y. G. Zhang, J. Tang, R. P. Liao et al., "Application of an enhanced BP neural network model with water cycle algorithm on landslide prediction," Stochastic Environmental Research and Risk Assessment, 2020.

[16] Y. G. Zhang, J. Tang, Z. Y. He, J. K. Tan, and C. Li, “A novel displacement prediction method using gated recurrent unit model with time series analysis in the Erdaohe landslide," Natural Hazards, vol. 105, no. 1, pp. 783-813, 2021.

[17] Y. G. Zhang and L. N. Yang, "A novel dynamic predictive method of water inrush from coal floor based on gated recurrent unit model," Natural Hazards, vol. 105, no. 2, pp. $2027-$ 2043, 2021.

[18] Y. G. Zhang, Z. Zhang, and S. Xue, "Stability analysis of a typical landslide mass in the Three Gorges Reservoir under varying reservoir water levels," Environmental Earth Sciences, vol. 79 , no. $1,2020$.

[19] Y. G. Zhang, S. Y. Zhu, J. K. Tan, L. D. Li, and X. J. Yin, "The influence of water level fluctuation on the stability of landslide in the Three Gorges Reservoir," Arabian Journal of Geosciences, vol. 13, no. 17, p. 845, 2020.

[20] Y. G. Zhang, Y. Zhu, W. Q. Zhang, and H. Liu, “Analysis of deformation characteristics and stability mechanisms of typical landslide mass based on the field monitoring in the Three Gorges Reservoir, China," Journal of Earth System Science, vol. 128, no. 1, 2019.

[21] B. Gong, Y. J. Jiang, P. Yan, and S. Zhang, "Discrete element numerical simulation of mechanical properties of methane hydrate-bearing specimen considering deposit angles," Journal 
of Natural Gas Science and Engineering, vol. 76, p. 103182, 2020.

[22] B. Gong, Y. J. Jiang, and L. J. Chen, "Feasibility investigation of the mechanical behavior of methane hydrate-bearing specimens using the multiple failure method," Journal of Natural Gas Science and Engineering, vol. 69, p. 102915, 2019.

[23] Y. F. Zheng, Extent of Hydronation and Pore Structure of LowWater-Binder-Ratio Cementitious Composites, Beijing Jiaotong University, 2018.

[24] F. De Larrard and T. Sedran, "Computer-aided mix design: predicting final result," Concrete International, vol. 18, no. 12, pp. 450-457, 1996.

[25] M. R. Jones, L. Zheng, and M. D. Newlands, "Comparison of particle packing models for proportioning concrete constitutents for minimum voids ratio," Materials and structures, vol. 35, no. 5, pp. 301-309, 2002.

[26] F. De Larrard and T. Sedran, "Mixture-proportioning of highperformance concrete," Cement and Concrete Research, vol. 32, no. 11, pp. 1699-1704, 2002.

[27] V. Kanniah, P. Wu, N. Mandzy, and E. A. Grulke, "Fractal analysis as a complimentary technique for characterizing nanoparticle size distributions," Powder Technology, vol. 226, pp. 189-198, 2012.

[28] M. Yu, W. Ni, and J. Liu, "Research on fractal dimension of particle-size distribution of ground iron tailing powder," Journal of Wuhan University of Technology, vol. 35, no. 2, pp. 2631, 2013.

[29] K. Yu and Z. S. Zheng, "Fractal features of particle-size distribution of powder," Chinese Journal of Materials Research, vol. 9, no. 6, pp. 539-542, 1995.

[30] Y. X. Guo, J. X. Gong, and J. Li, "Impacts of the mixing amount of limestone powder on the mechanical performance and durability of concrete," Journal of Building Materials, vol. 12, no. 3, pp. 266-271, 2009.

[31] R. W. Burrows, The Visible and Invisible Cracking of Concrete, American Concrete Institute, 2012.

[32] Y. Li, K. R. Wu, S. X. Wang et al., "Self-contraction performance of set cement with mixtures," Journal of Building Materials, vol. 4, no. 1, pp. 7-11, 2001.

[33] L. Xie, Influencing Factors of Early Self-Contraction of Concrete and Forecast Modelling, Hohai University, 2007.

[34] P. K. Mehta and P. J. M. Monteiro, Concrete: Microstructure, Properties and Materials, McGraw-Hill, 2006.

[35] Z. W. Wu and H. Z. Lian, High-Performance Concrete, China Railway Publishing House, 1999. 